\title{
Heuristic Catenary-based Rule of Thumbs to Find Bending Moment Diagrams
}

\author{
Maria Rashidi, Ehsan Sorooshnia* \\ Centre for Infrastructure Engineering at the School of Computing, Engineering and Mathematics (SCEM), Western Sydney \\ University, Penrith, NSW 2751, Australia
}

Received November 8, 2019; Revised April 28, 2020; Accepted May 13, 2020

Copyright $(2020$ by authors, all rights reserved. Authors agree that this article remains permanently open access under the terms of the Creative Commons Attribution License 4.0 International License

\begin{abstract}
There are numerous nature-inspired curves representing certain structural behaviour being utilised in form-finding process by some famous architects. By closely scrutinising these forms, some interrelated morphological analogies between different structural forms and functions, such as the similarity between free-standing tension-only elements and the shape of bending moment diagram of a beam under the same load condition, can be explored. Most studies in the field of statics principles have only focused on developing numerical and mathematical approaches which are not suitable for practitioners who prefer quick access to the general forms. This paper first gives a brief overview of the most common archi-structural forms through the history of the architecture, and attempts to find the shape of bending moment diagrams through a new simple heuristic method based on drawing an analogy between natural tension-only forms and the diagrams. The purpose of this research is to propose a shortcut to diagram drawing substituting the general time-consuming methods as well as enhance the architects' perception of bending behaviour of a structural element. A holistic approach is utilised, integrating the natural curves, bending moment diagrams and some rule of thumbs used to define the tapered beam or portal frame general shapes. This simple non-computational method can ease the design process. It will also be useful for educational purposes as well as pre-design phase conception including identification of the critical points of bending elements as well as designing tapered beams and portal frames.
\end{abstract}

Keywords Catenary, Funicular, Heuristic Approach, Bending Moment Diagram

\section{Introduction}

Funiculars are amongst the important forms which are sources of inspiration in sciences, industry and architecture. In this context, there are two essential terms: Funicular and Catenary. By definition, Funicular form stands for having the form of a rope usually under tension only or any form associated with. The term Funicular is the adjective of Funiculus which means "a bodily structure suggesting a cord" [merriam-webster.com]. The Catenary is a curve which forms when a cable or chain is supported at its ends and subjected to its only weight. The curvature described by an even chain hanging from two props in a uniform gravitational field is labeled a Funicular, a name apparently coined by Thomas Jefferson. If the sag is small, so that the weight is about uniformly distributed, the curve is close to a parabola $\left(y=a x^{2 n}, n \in N\right)$, a quadratic curve, but the catenary is a hyperbolic cosine curve, $\mathrm{y}=\operatorname{acosh}(\mathrm{x} / \mathrm{a})^{1}$

(Figure 1).[1] Etymologically, the word catena, a Medieval Latin word which means a series of connected things [merriam-webster.com] is the origin of catenary.

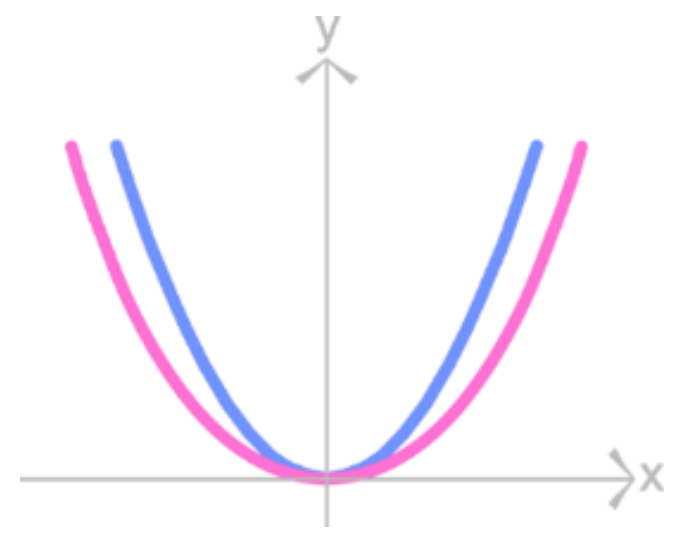

Figure 1. Parabola (in blue) and Hyperbola (in magenta) in Cartesian coordinate system

Generally, when some plummets are hung down from a

${ }^{1} \mathrm{x}$ is measured from the lowest point. 
cable or another flexible tension element in horizontally equal distances (uniformly distributed on horizontal projection), cable forms Parabola (Fig. 2-a) and when distances are equal along the cable length (uniformly distributed load along the length of the cable), it forms Hyperbola (Figure 2-b). In the context of building terms, Hyperbola usually named Catenary in both situations only tension forces developed in cables. It appears in some natural and architectural forms since ancient times. It can be seen numerous catenary-inverted arches and vaults in the history of architecture all over the world. These forms are among lesson learnt from nature to find optimum forms to transfer loads efficiently.

Despite the fact that Galileo guessed the form of a pendent chain as a parabolic curve[2], the application of the catenary in the fornicate construction is referred to Robert Hooke, Jardine says: "Hooke recorded his rationale for such a masonry dome shape, based on the imagined inversion of a hanging catena."'[3]
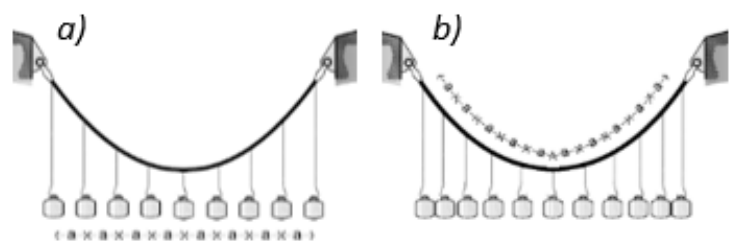

Figure 2. a) Parabola and b) Hyperbola (catenary)

\subsection{Funicular Forms in Building Design}

It could be found mentioned forms everywhere in nature. The trajectory of a projectile is an example of a parabola shape. When throwing a ball, it tracks a parabolic path to fall down on the ground (Figure 3), or a bouncing ball along with gyration and air resistance, causes the curve to diverge somewhat from the perfect parabola (Figure 4). In addition, the shape of the rise and falling water in fountain trajectory is also parabola (Figure 5). The mentioned forms are not limited to a movement but also could be found in lighting shape (Figure 6).

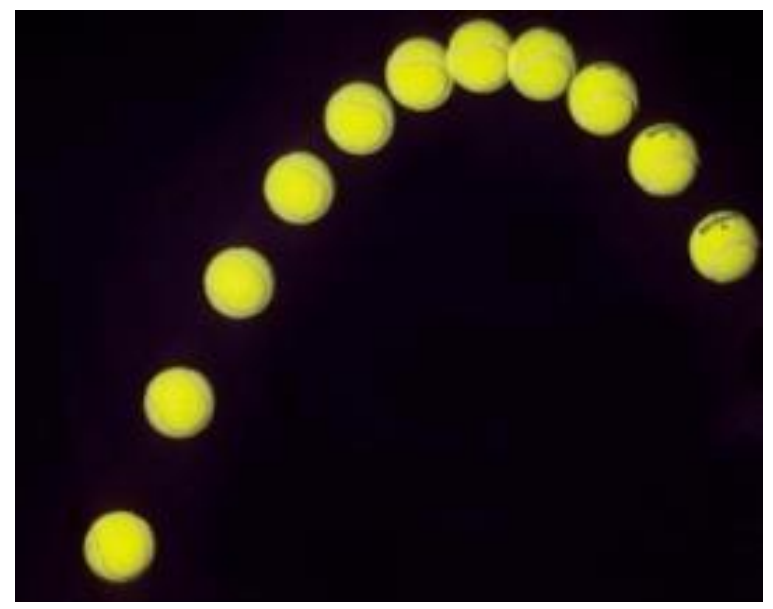

Figure 3. Parabolic path for the trajectory of a projectile. (Source of image: Burlington-Edison School)

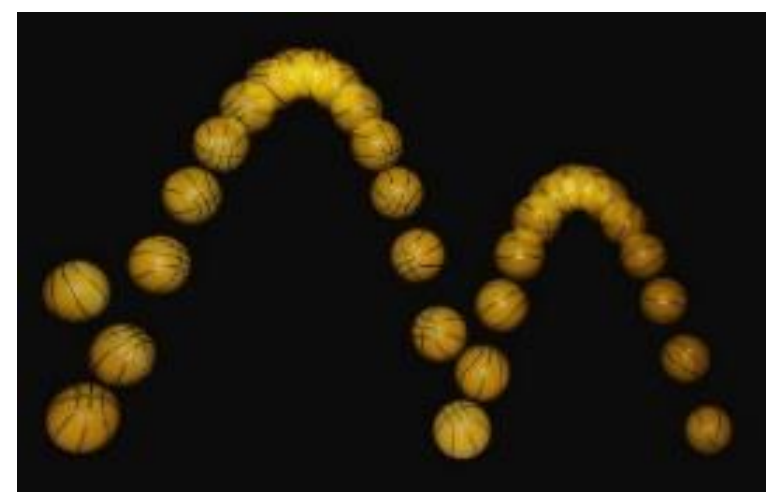

Figure 4. A bouncing ball captured with a stroboscopic flash at 25 images per second. Its trace shapes a parabola. (Source of image: Physics Central.com)

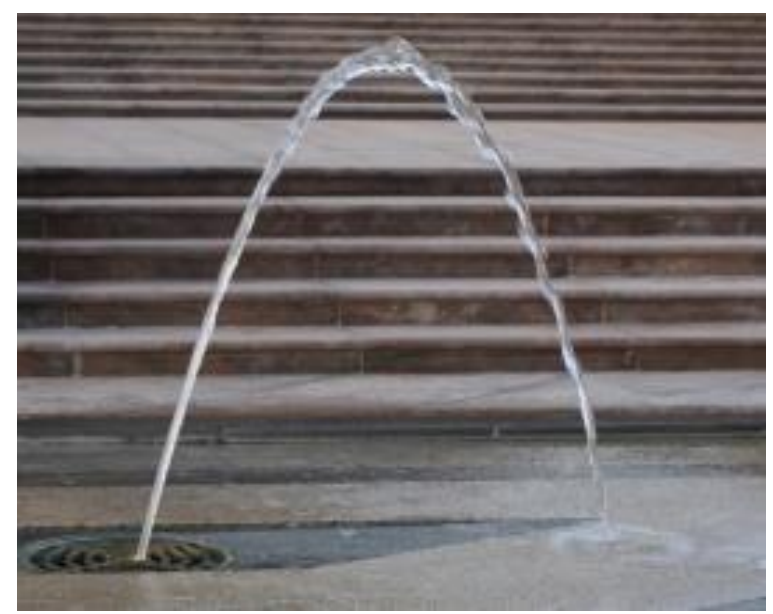

Figure 5. Parabolic trajectories of water in fountains. (Source: Courtesy of Pooya Ale-Davood)

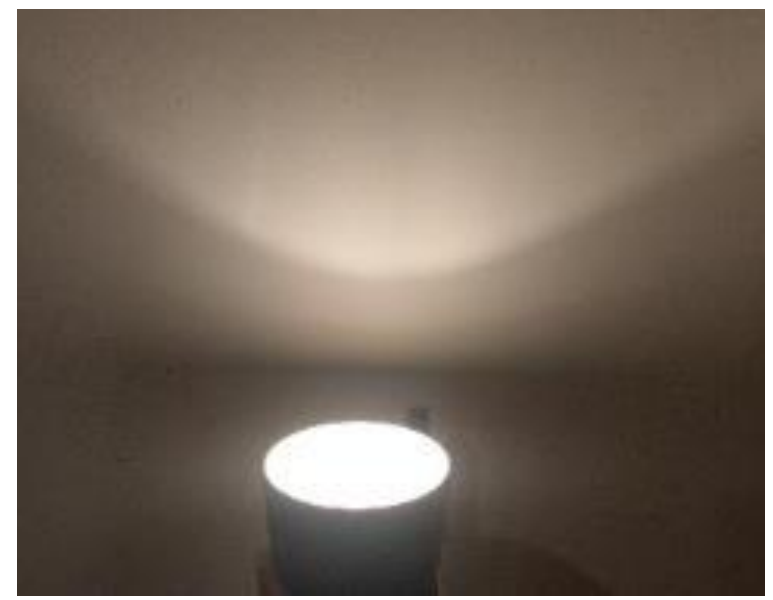

Figure 6. Light spreading shape on a wall forms a parabola (Source of image: authors)

Many of old or new structural morphologies can be characterised as primarily in the state of pure tension or compression. These two dimensional (as a flexible cable) or three dimensional (as a flexible membrane) structures can be built by the form of catenaries (for tension only systems) or reversing catenaries (for compression only systems). So old-time architects found they could construct a thrust line 
of arches and domes by inverted catenary (Figures 7 and 8).

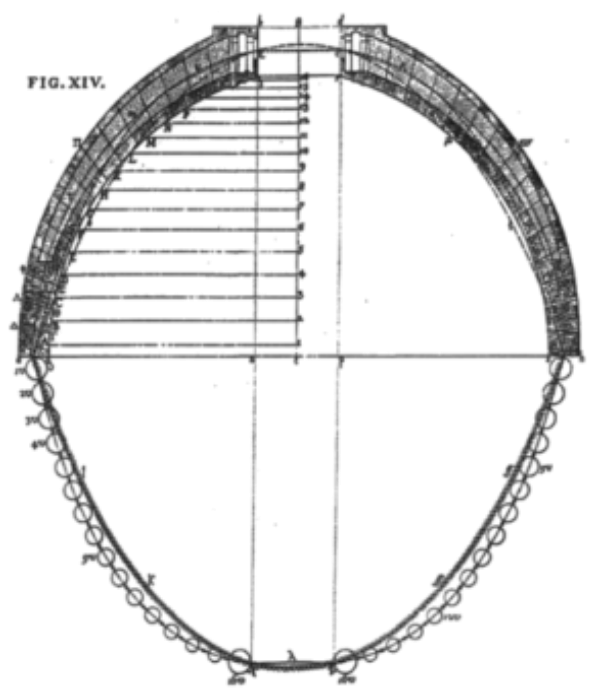

Figure 7. Construction of St. Peter's dome (an early but not modern analysis method) by inverting catenary. (Source: [4])

Schodeck and Bechthold believe: "The easiest way to determine the funicular response for a particular loading condition is by identifying the exact shape of flexible string which would deform to under a load. Such a shape is called the tension funicular. Inverting this shape exactly yields a compression funicular."[5]

In relation to structural morphology, funicular-based systems are forms which depend on the direct effect of forces and attain the most optimum structural form. On the other hand, the equilibrium static form of cables subjected to forces (individual or distributed) defines funicular. The best-known application of such an approach in designing structure is Colònia Güell designed by Antonio Gaüdí (Figure 7). Motro said: "He was inspired by nature, took advantage of the duality of compression and tension and defined compressed systems by inverting entirely tension systems, in this category, forms and forces are biunivoque; each system of distinct forces is associated with a different form.' $[6]$

\subsection{Examples of the Parabola in Structural Morphology}

Funiculars have a great influence on Antonio Gaüdí’s architecture and make his designs near optimum. He believed that he had found optimum forms because the artist God created it. Gauidí used the empirical method of hanging weights, equal to the weights of the masonry, from networks of flexible cords and then notionally inverting them.[8] (See Figure 8).

It is telling that such masters of architecture learned when they wanted invert catenary to find the form of an arch, the cross-sectional dimension should increase. This is the main reason why arches are thicker than tension-only systems usually. Another reason for making arches thicker was the probability of changing loads on the structure. When loads change from catenary-made arches, the form of arch wants changes slightly and this form changing may cause the arch to collapse. By making arch thicker, the probability of collapsing decreases because the arch form includes the catenary line ${ }^{2}$.
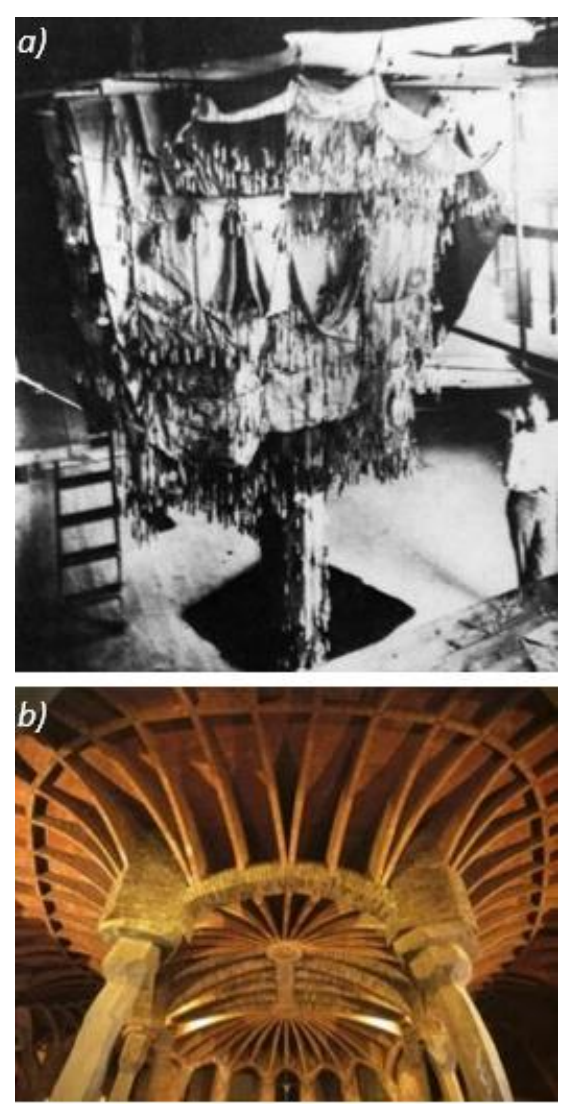

Figure 8. a) Wire model for study of structural forces. (Source:[7]); b) Interior view of Colònia Güell, Catalan, Spain, Antonio Gaüdí, 1899 (begun) which designed in brick and stone masonry by inverting funicular forms to find the best shape of arches (Source of image: Gaudidesigner.com)

Henceforward many designers took this design approach to create masterpieces both in classic (masonry) and modern architecture (moment resistant materials). So Mother-Nature-helped architects to create immanent works all over the world through the $19^{\text {th }}$ and $20^{\text {th }}$ centuries. For example, Cèsar Martinell i Brunet used parabolic masonry arch for a structure to form Celler de Sant Cugat in Spain (Figure 9). A parabola is a second-degree function which its standard form is: $y=a x^{2}$ which has been proved in the previous section. If you imagine a classical masonry arch subjected to its own weight (Figure 9 and 10), it is provable that the best form for transferring load through the arch is the parabola[9] because, under this form, arch bears only compression stress (which is the best for material properties). When a masonry arch transfers the only compression, the

\footnotetext{
2 Which is also called thrust line.
} 
risk of buckling and tensile cracks mitigates.

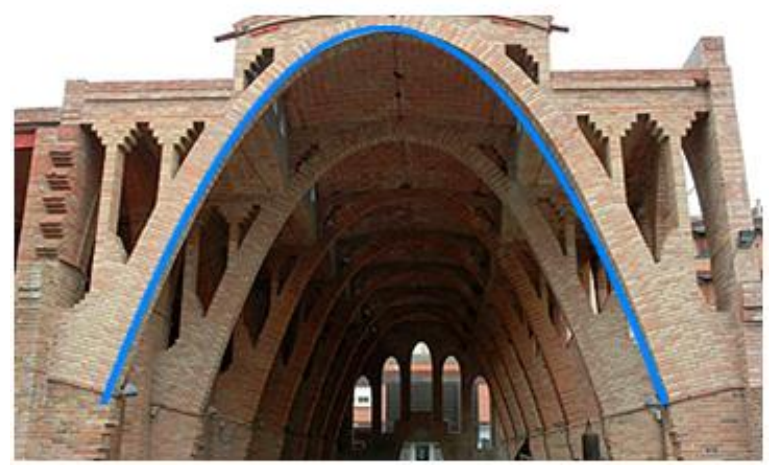

Figure 9. Masonry parabolic arch in Celler de Sant Cugat, Cèsar Martinell i Brunet, Spain, 1921. And form of the parabola (in blue) on it. (Source: http://patrimoni.gencat.cat)

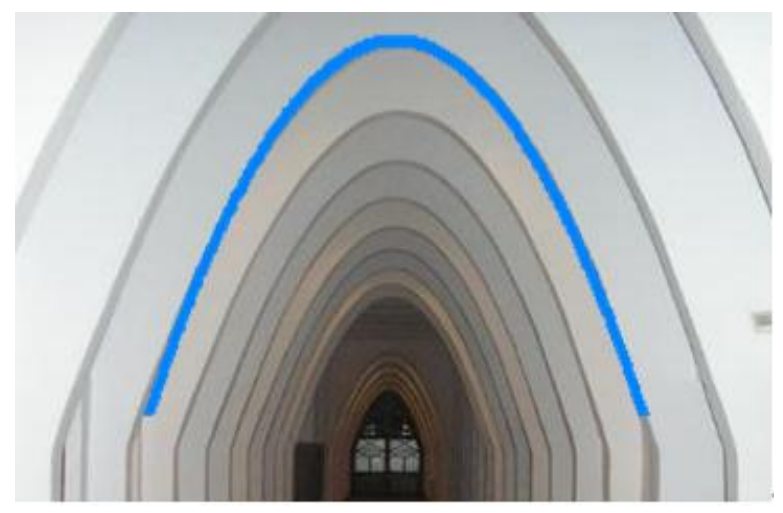

Figure 10. Parabola form on a set of repetitive parabolic arches in Colegio de las Teresianas, Barcelona, Spain, Antonio Gaüdí, 1890. (Source of image: touristeye.com)

Another example of parabolic optimum structure is the Airship hangar by Eugène Freyssinet. The overall form of its ribbed reinforced concrete thin shells is a parabola. The tapered form of arches decreases upward. Choose of catenary form posed pure compressive stress on arches and prevented big tensile stresses on the structure (Figure $11)$.

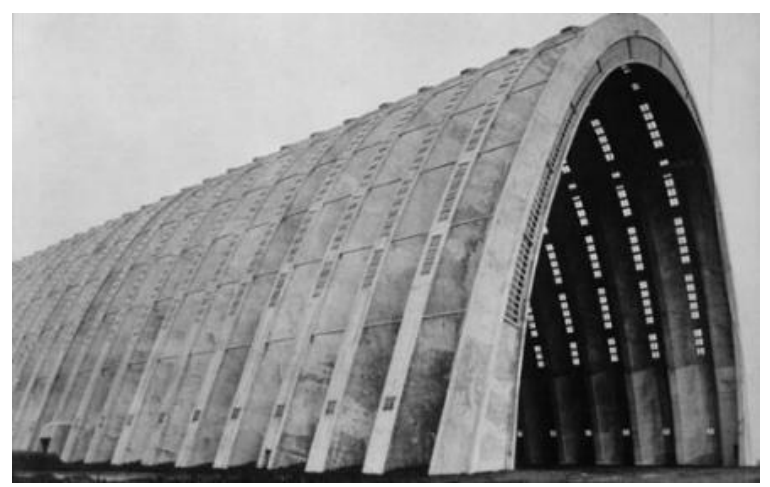

Figure 11. The two hangars are $175 \mathrm{~m}$ long, $91 \mathrm{~m}$ wide and $60 \mathrm{~m}$ high. Connecting a series of parabolic arches formed an undulant vault similar to corrugated sheet, Orly (near Paris), France, Eugène Freyssinet, 1923. (Source of image: arquiscopio.com)

Some architects use the mentioned approach to design modern building and facilities. Two hinged glue-laminated timber arches are the main structure of winter garden in Sheffield designed by Pringle Richards Sharrat Architects (Figure 12). BRT Architekten also designed some buildings in a similar approach by different height to span ratios (Figure 13).

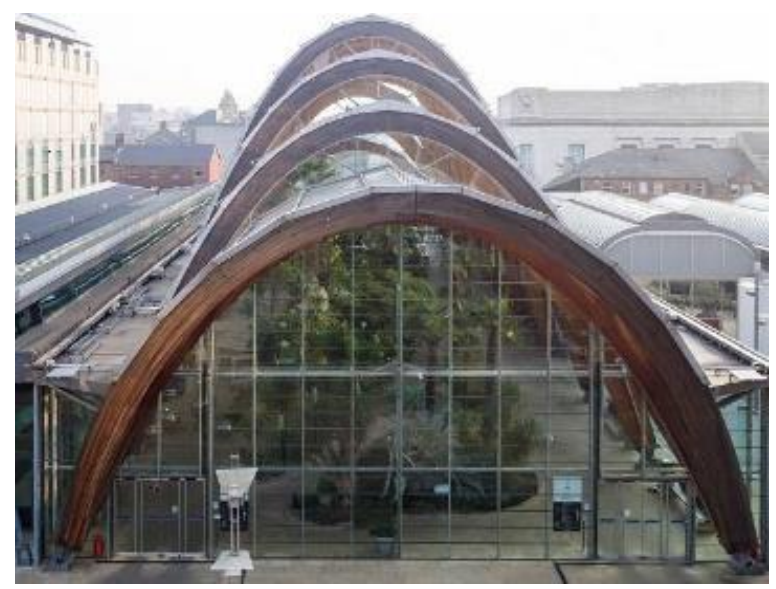

Figure 12. Glue-laminated two-hinged parabolic arches in winter garden, Sheffield, UK, Pringle Richard Sharrat Architects, 2002. (Source of images: prsarchitects.com and sheffieldnewsroom.co.uk)

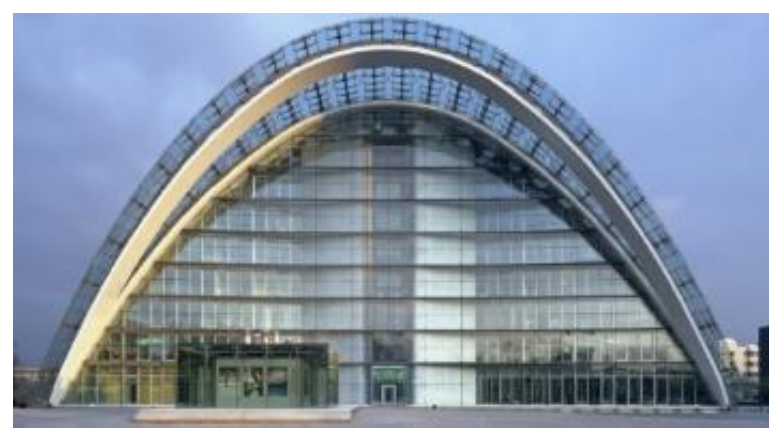

Figure 13. A parabolic two-hinged arch in Berliner Bogen Office Building, Hamburg, Germany, BRT Architekten. (Source of images: brt.de)

\subsection{Hyperbola Form in Contemporary Structural Design}

The hyperbolic form also could be seen in nature. Lighting on a wall, shapes hyperbola. When light source applied on the body of a wall alongside its height, the shape of light spreading forms hyperbola (see Figure 6).

An example of a hyperbolic form of modern structures is $192 \mathrm{~m}$ high Saint Louis Gateway Arch (Jefferson Memorial) that is designed by hands of young Finnish immigrant named Eero Saarinen. He and Hannskarl Bandel inverted a catenary to form the arch (Figure 14). Consider one of the Mainstone's opinions about this monumental: "Indeed, having been built solely as a monument and without any of the stabilizing additions that contribute to the stability of most other arches, it goes for beyond what would normally be considered the proper use of the form." $[10]$ 


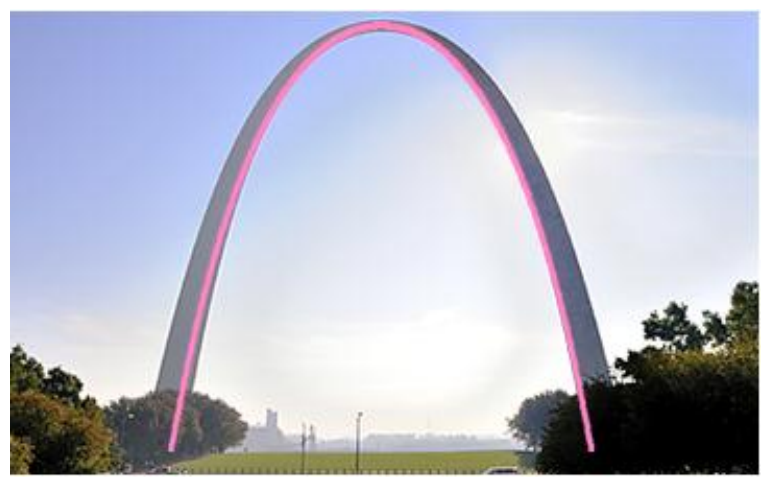

Figure 14. Structural expressionism form of the memorial arch resulted in inverting catenary in Saint Louis Gateway Arch, Saint Louis, Missouri, USA, Eero Saarinen (Architect) and Hannskarl Bandel (structural engineer), 1965 and hyperbola form on it. (Source of image: interestingamerica.com)

Using catenaries and optimum tension-only systems for structural form-finding is not limited to arches and vaults. Some famous engineers like Frei Otto and Heinz Isler took a similar strategy to design very successful and efficient structural forms that are structurally and aesthetically winsome. He also believes structural form-finding approaches with respect to architectural aspects. Otto loaded a tension net grid with nails to find the best form of his concept (Figure 15-a). Then he used this approach again for design a gridshell. (Figure 15-b).
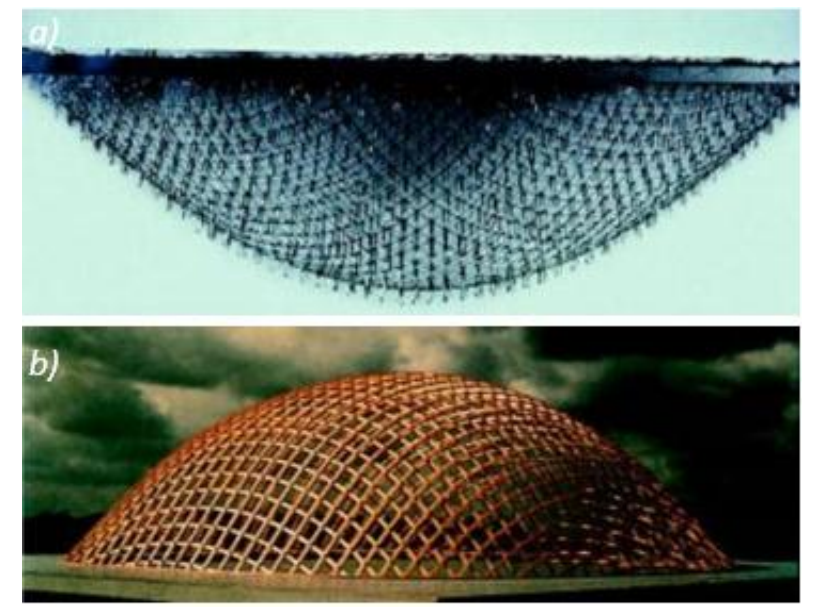

Figure 15. Process of form-finding by Frei Otto: a) The suspended model composed of textile threads, loaded with u-nails, for the gridshell; b) Built gridshell structure. (Source: Freiotto.com: () Atelier Frei Otto Warmbronn)

Hereafter this form of gridshell would be a pattern for designing several timber gridshells. The Savill Gardens Gridshell by Glen Howells Architects, The Weald \& Downland Open Air Museum gridshell by Edward Cullinan Architects are examples of using Otto's gridshell modelling.

Heinz Isler -a famous Swiss engineer noted for his thin shell structures- is another designer who used catenaries for form-finding. He is considered as one of the eminent pioneers in thin shell structures all over the world. John
Chilton states: "Architecture and engineering are just two aspects of one thing."[11] So Isler saw architecture and structure as two integrated parts of a unity. (Figures 16 and 17).

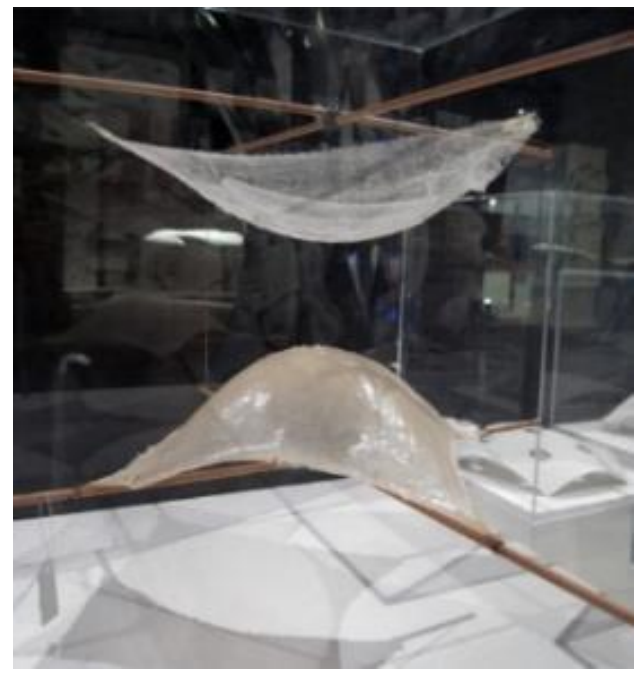

Figure 16. Hanging fabric and inverting its form for thin shells by Isler. (Source: designboom.com)

Isler's reinforced concrete thin shells are very reputable because they are optimum, minimal, beautiful and elegant. In relation to free-form thin shells, he proposed on-ground-moulded shells instead of moulding upon scaffolding (which is very expensive) using an inflated rubber membrane-like method Dante N. Bini suggested. Isler hung the cloth to find the best form then reversed it for the shells. "Many of the shells that Isler designed were constructed using these methods. He would build small-scale models using hanging fabric, freeze the three-dimensional shape using epoxy resins and then just scale the model up. At the time when Heinz Isler started designing shells, this was the only way one could design them. Computers were not powerful enough to support structural analysis software for spatial structures. Thus, there was no such software developed at the time. Therefore, very precise instruments were used to measure the small scale models so that the real structures could be drawn in full scale as a scaled-up version of the models."'[12]

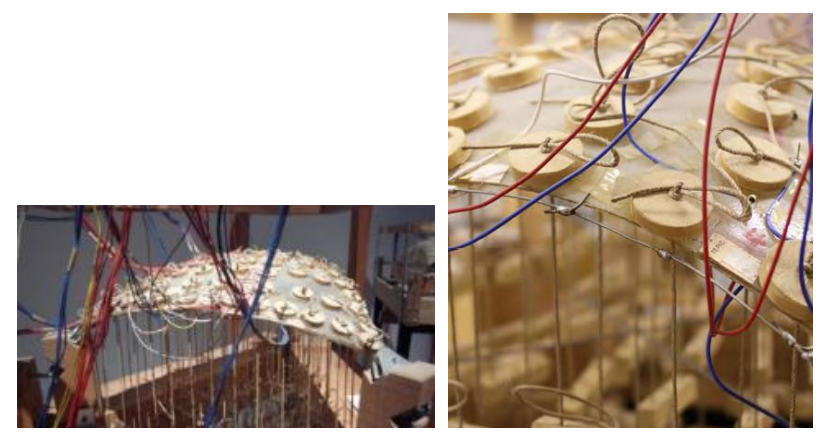

Figure 17. Detail of Isler's models for form-finding of shells. (Source: [13] and Freiotto.com) 
He says: "In the design of a building, some rules have to be observed: for instance, good proportion, simplicity, honesty, etc. The same rules are valid when designing a building with shells. The foremost task lies, in the opinion of the author, in leaving off everything that is not necessary. A well-shaped shell is such a dominant structure, that it needs no addition of other dominant elements. On the contrary, it forbids them. The shell is the supporting structure and the space enclosure at the same time. So it cannot be but honest."'[14]

Allegiance to natural forms makes his thin shells structurally efficient as well as aesthetically elegant. Whereas the forms were an inversion of catenary (tension only) forms, just bear compression thus Isler's shells were pure compressive and because mainly working in compression did not need laterally stiffening ribs. This was one of the reasons made him able to gain a very low thickness to span ratio.

\section{Discussion}

\subsection{Catenary-based Form-finding of Bending Moment Diagrams of Beams}

Beam diagrams like SFD $^{3}$ and BMD $^{4}$ are very useful prerequisites for designing and understanding the behaviour of structural elements (especially frames). The stresses and deflections in a beam to be a function of Bending Moment, so calculating how this quantity differs along a beam is important.[15] Knowing the internal shear forces and bending moments to be resisted is crucial to determine the size of a beam of a given material, and determining the deflection of a beam in every points along. Hence, we can assume finding the BMD and its peak as first step of designing beams.

Sometimes finding the diagram drawing is the most important issue to help us pinpoint the location of maximum internal stresses. The key problem with conventional approaches is that applying them finding diagrams requires hard and time-consuming calculations e.g. method of sections ${ }^{5}$ or integral method ${ }^{6}$. By reason of such putting over processes, heuristic and simplified methods that do not need complicated calculation and producing some extra algebra, will accogliered by architects and students of civil engineering.

\footnotetext{
3 Shear Force diagrams

${ }^{4}$ BMDs

5 In Method of Sections we should cut off some sections (cuts) of the beam upon every changing the load and supply equilibrium equations and gain equations of shear force and bending moment for every section of beam. After that we can draw diagrams.

${ }^{6}$ In Integral Method we should first integrate of loading equation for every load changing on beam to find shear force equation. Then integrate this equation to find bending moment equation. After that we can draw diagrams.
}

Sometimes it is necessary to know where maximum bending moment occurs without numerical aspects. In such cases, fast form-finding approaches can be very useful. Particularly, for architects that usually disincline numerical and calculative methods.

As one of the lesson learnt of nature, we found a heuristic method, bodes the form of BMD of a beam resembles the catenary form that supports the same loads posed on a beam. So trying to systemize a new approach and define sequential algorithm for nature-inspired form-finding for BMD.

For example, consider a simple beam under a concentrated load at the centre (Figure 18-a). If such a load is applied on a weightless cable (Figure 18-b) and assume a single plummet hangs down from the centre of the cable, it takes V shape; now if by reversing this form ${ }^{7}$, bending moment form of that beam is found (Figure 18-d). Using of such fast and easy way to find BMD can assist architects and structural engineers to save time in the understanding critical region of structural elements, reinforcing, retrofitting and designing well-designed tapered form beams.

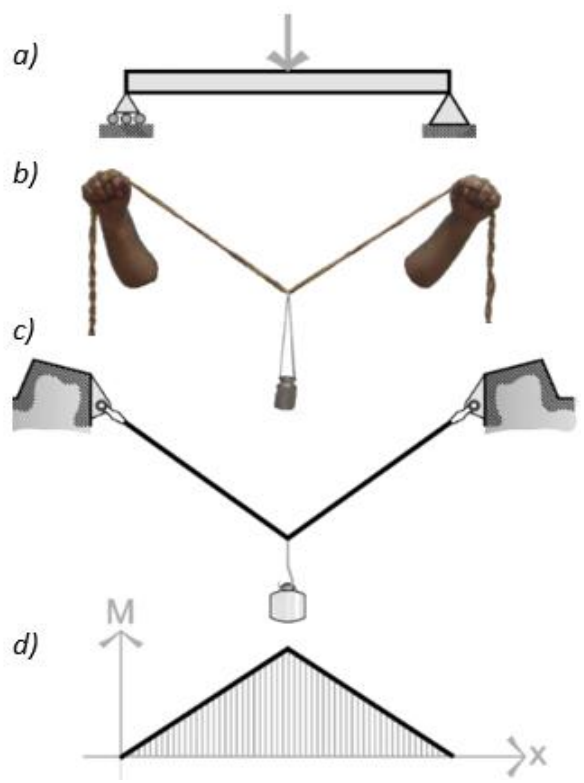

Figure 18. a) A simple beam with concentrated load at centre; b) Catenary of loading (V shape); c) Modelling of BMD upon catenary; d) Reversing catenary form to find BMD

Here to pursue induction approach to develop this method to all types of beams. By increasing the number of concentrated loads, their weights then will assume distributed loads. After that, the examination of our method will commence to conclude and systemize it. In this step, it will be tested under a combination of several loads and several supporting conditions of beams.

7 We take the positive bending diagram upwards. 
In the second example two concentrated loads on a simple beam are applied (Figure 19-a). For fast-finding $\mathrm{BMD}$, it is assumed that the mentioned loads are posed on a flexible weightless cable. The cable under this loading condition takes symmetrical trapezoidal form. Then, by converting this form, the BMD is found easily (Figure 19-d).

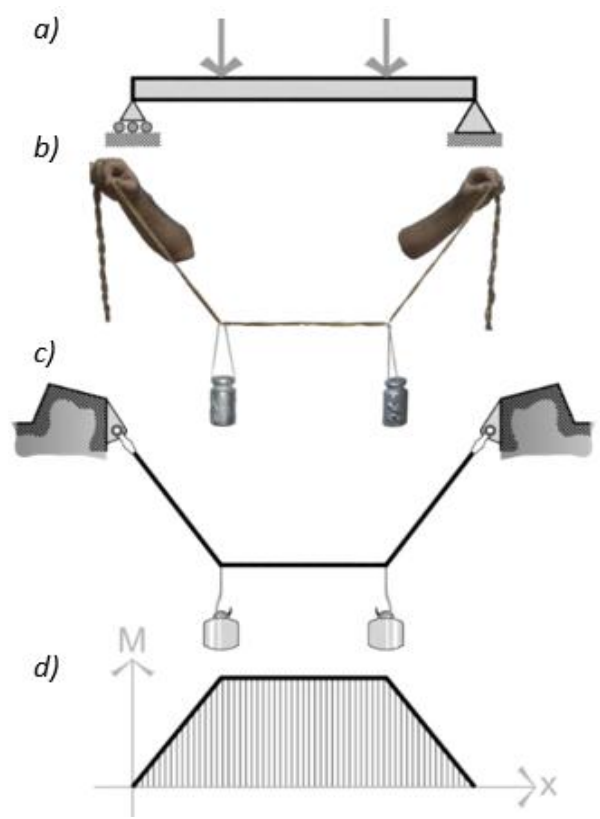

Figure 19. a) A simple beam with two equal concentrated loads symmetrically placed; b) Catenary of loading (symmetrical trapezoidal form); c) Modelling of BMD upon catenary; d) Reversing catenary form to find BMD

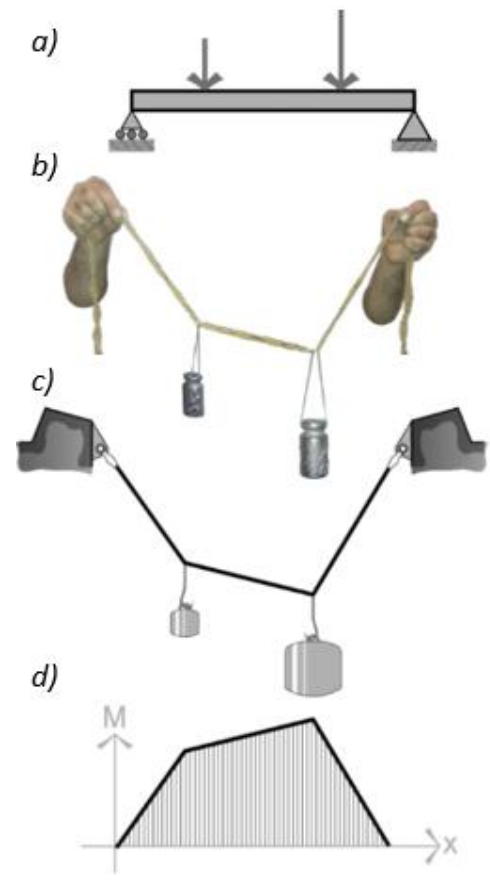

Figure 20. a) A simple beam with two unequal concentrated loads symmetrically placed; b) Catenary of loading (asymmetrical trapezoidal form); c) Modelling of BMD upon catenary; d) Reversing catenary form to find BMD
In the third example, by changing the magnitude of one of the concentrated loads and apply it on the beam (Figure 20-a), the symmetrical trapezoidal form of cable changes will fall under bigger load. So the cable form will be an asymmetrical trapezoidal form (Figure 20-b). By converting this shape, BMD of a beam under two unequally concentrated loads is drawn (Figure 20-d).

Yet consider cable behaviour under concentrated loads and method of finding BMD of beams by using catenary. Henceforward distributing loads on the beams and examining how cable behaves under such loads is the next step.

For another example, consider one of the most famous beams, a simple beam with simply distributed load (Figure 21-a). If some similar plummets (with equal horizontal distances) are hung down from a weightless cable (Figure 21-b), as mentioned in the previous section, it takes parabola shape. Then by reversing this shape, the form of BMD of the beam is found (Figure 21-d).

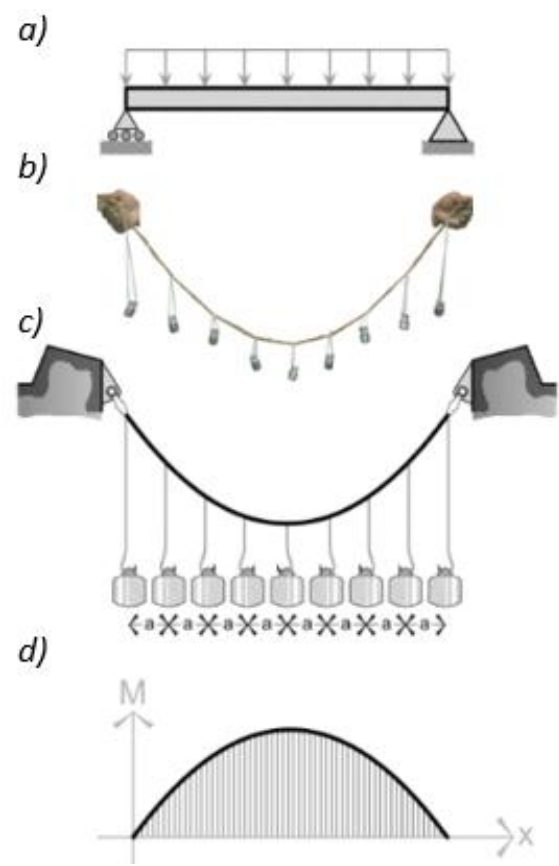

Figure 21. a) A simple beam with uniformly distributed load; b) Catenary of loading (parabola); c) Modelling of BMD upon catenary; d) Reversing catenary form to find BMD

In the combination of concentrated with distributed loads, by adding a concentrated load at the centre of the beam illustrated in Figure 21, the catenary form of the cable form changes a little and appears a ridge at the point of applying concentrated load and takes shape like a Gothic arch (Figure 22-b).

In Figure 23-a, by removing half of the uniformly distributed load posed on the beam, there is a simple beam with partly loaded by the uniformly distributed load. For modelling catenary with such loading condition, there is a cable that half of it is under uniformly similar hanging plummets. When we hold a flexible weightless cable in our hands and apply some plummets just on half of it, it can be seen that the half of cable that is under distributed 
load, takes parabolic form and another half, takes the linear form (Figure 23-b).

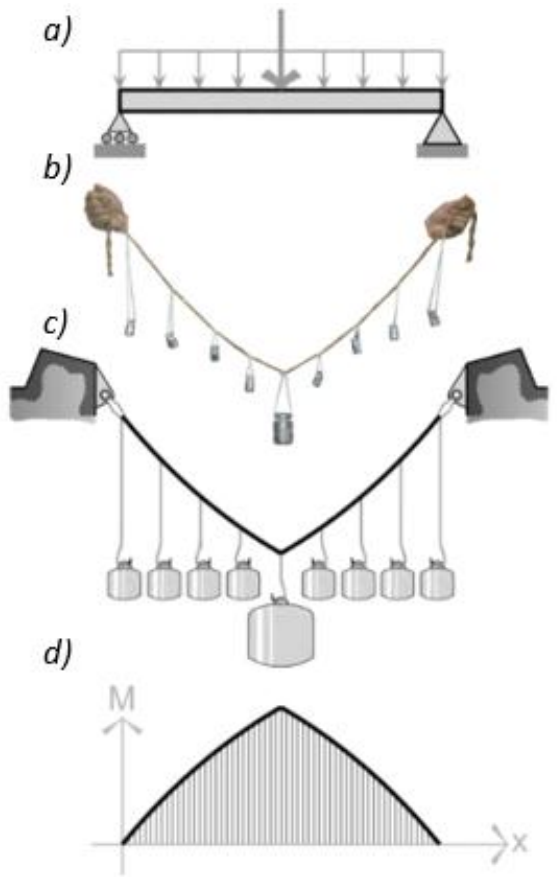

Figure 22. a) A simple beam with uniformly distributed load; b) Catenary of loading (ridged parabola); c) Modelling of BMD upon catenary; d) Reversing catenary form to find BMD

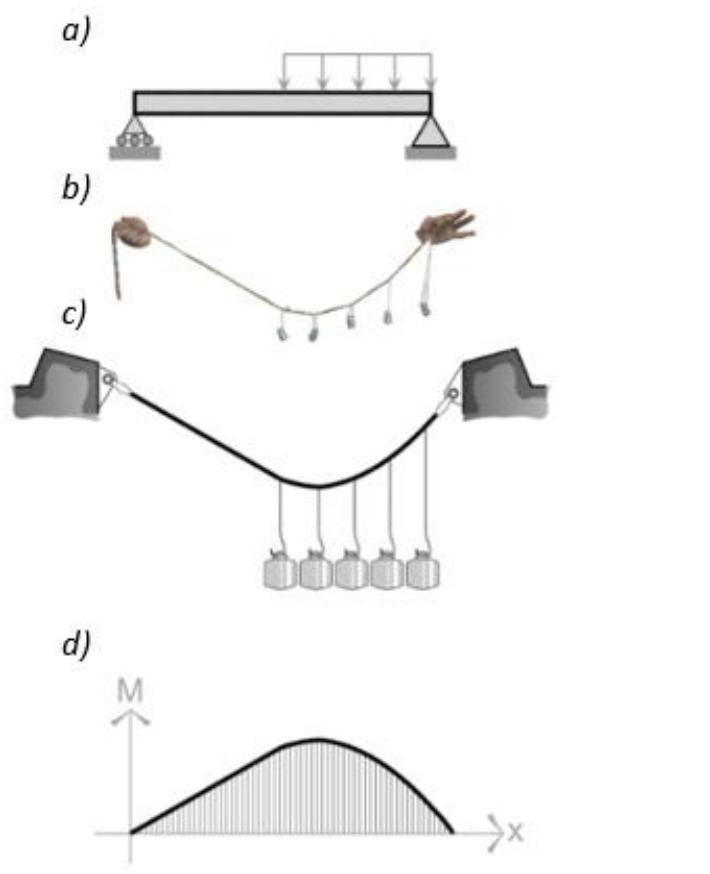

Figure 23. a) A simple beam with partly uniformly distributed load; b) Catenary of loading (semi parabola and semi line); c) Modelling of BMD upon catenary; d) Reversing catenary form to find BMD

After the mentioned examination, it can be concluded some rules of the new method:

- $\quad$ Concentrated (point) load make a ridge on the cable form.
- $\quad$ Uniformly distributed load bring cable to parabolic form.

- The region of cable is not under loading takes inclined linear form ${ }^{8}$.

After form-finding, in the next step, categorising of modelling supports condition, as a rule, is aimed. The experiences showed that there are three general rules for modelling supports:

- The free end of beams should model as ground support (Figure 24-a).

- $\quad$ Fixed (rigid) supports of beams should model as a pylon (Figure 24-c).

- When there is a simple end-support (hinged or roller) it should be assumed it as headland support (Figure 24-b).

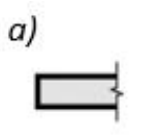

b)
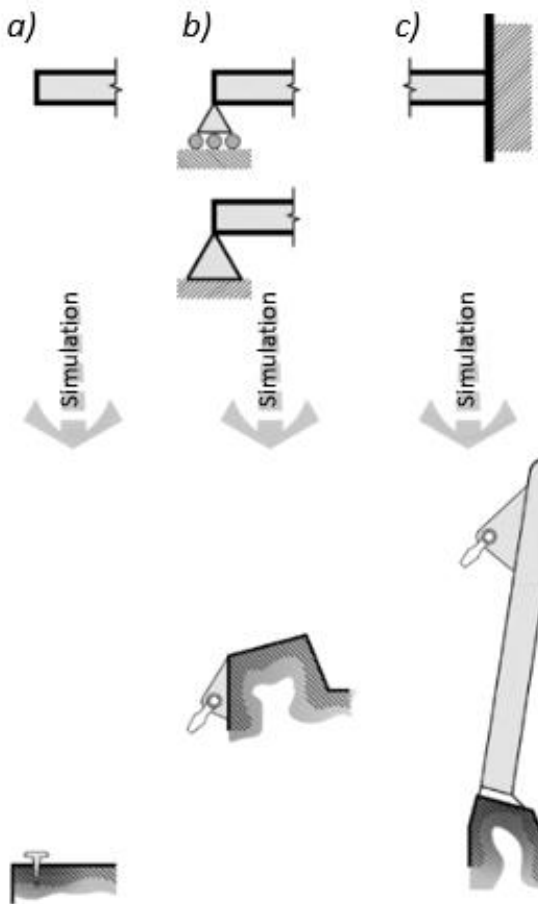

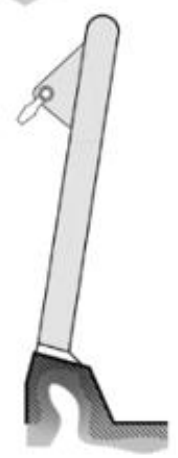

Figure 24. a) Free end of beam models as ground support; b) Simple support (hinged or roller models as headland support; c) Fixed (rigid) support models as pylon

It worth noting that during the support modelling it should be observed height scale of support that ground support should be the lowest one, then headland support should have moderate height and pylon support should be the highest one. It is an exception for modelling support that we should treat simple supports placed in the inter-mediation of beam-like pylon (see Figure 26).

Hence, to draw BMD by this proposed method, first supports (ground, headland or pylon) should be modelled, then assuming a flexible weightless cable between

${ }^{8}$ There are some exceptions in symmetrical beams with no load region that diagram shapes a horizontal direct line. 
supports and finally apply loading of the beam on the cable finds the catenary form of cable. Afterwards considering a lower level of support as $\mathrm{x}$ axis, mirror the catenary around it.

As another example, consider a cantilever beam under uniformly distributed loading (Figure 25-a). In the first step, supports are defined and simulated. The left support is a rigid one so it should be modelled as a pylon. The right support is a free-end one so modelled as ground support. In the second step assuming a cable tied between pylon and ground is posed some plummets similarly distanced. The cable takes a parabolic form that falls down from pylon but cannot go down beneath the ground. So it abuts the ground (Figure 25-b). Should keep in mind that our simulation method is an abstract method and the ground should not be thought of as the earth which plummets cannot hang down aside. In the last step, the BMD is drawn. Between ground and pylon, the ground is the lower, so the ground was assumed as $x$ axis and mirror the shape of catenary around it (Figure 25-c).
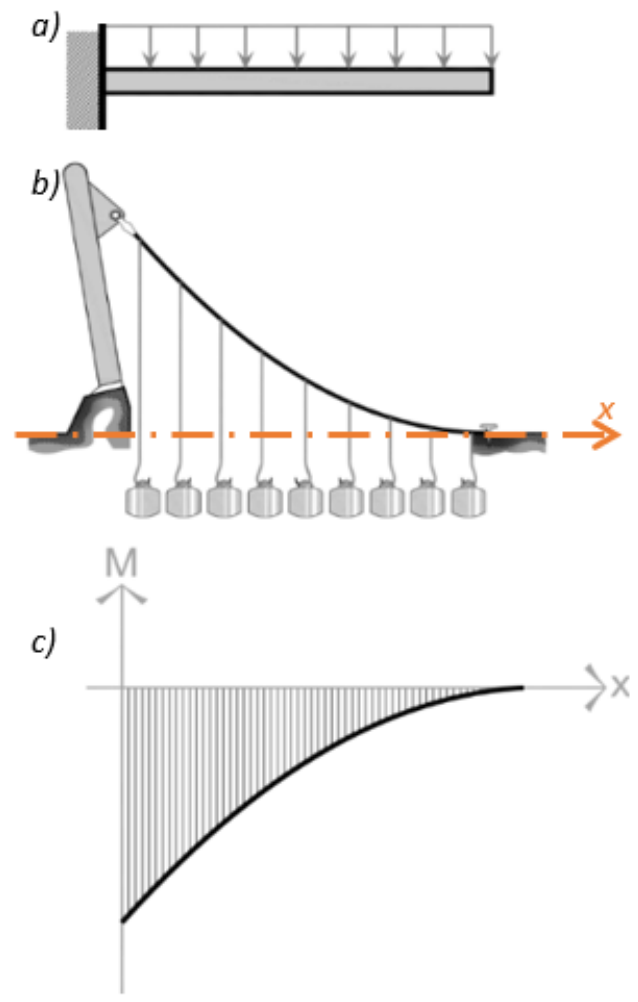

Figure 25. A cantilever beam with uniformly distributed load

This method is not limited to determinate beams and hyperstatic beams which can be simulated as well. Another example is Figure 26-a, a beam is constrained by rigid and simple support at its ends and is subjected to uniformly distributed load. Left support will be modelled as a pylon and right support is like headland support. Uniformly distributed load makes cable parabola and will fall down about both supports (Figure 26-b). In the final step, lower support (headland) will play the role of $x$ axis to mirror the shape. This process also occurs about any other beam. As mentioned before, simple supports at intermediate of the beam is treated like a rigid one (Figure 26-c).

A continues hyperstatic beam which is very usual in multi span buildings is simulated in Figure 27 under the same considerations described before.
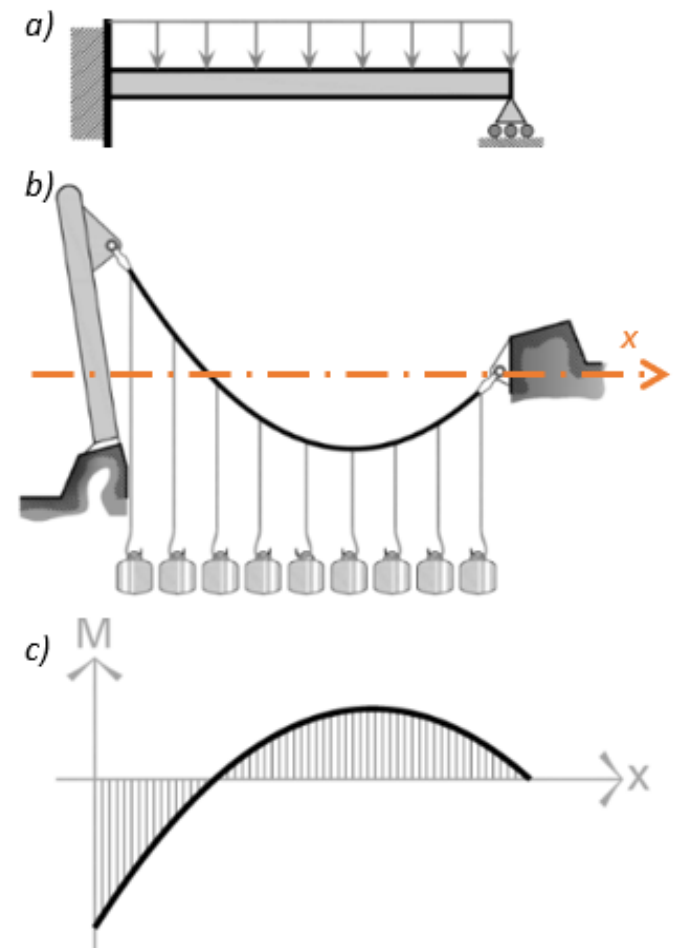

Figure 26. A hyperstatic beam with uniformly distributed load

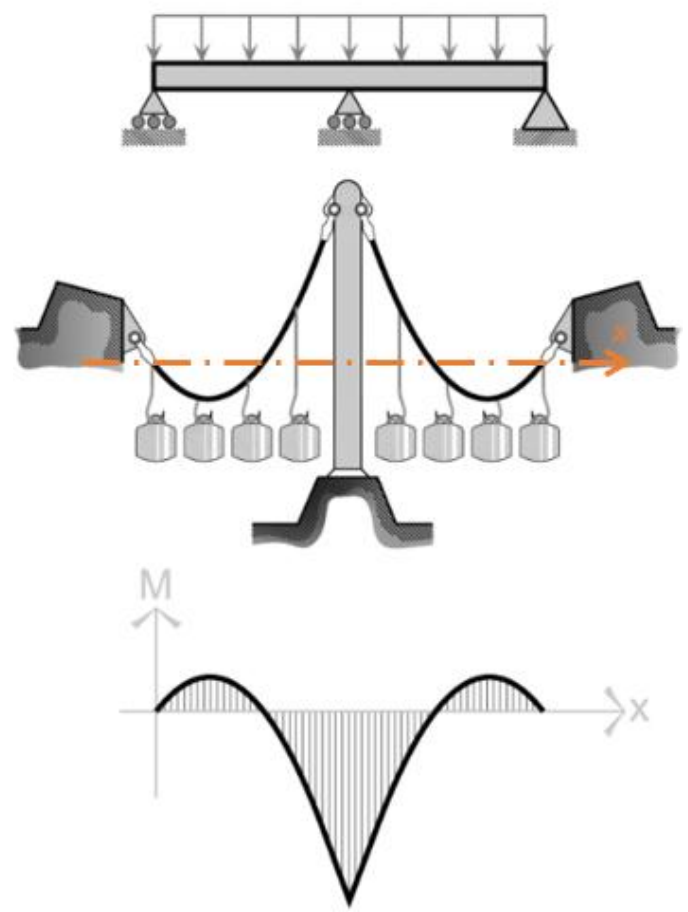

Figure 27. Finding BMD of another three supported hyperstatic beam with uniformly distributed load 
It should be noted that the proposed method has two exceptions in modelling. So, a number of important limitations need to be considered. First, when there are beams fixed at both ends beams, the mirror axis ( $x$ axis) should be taken in the lower half of pylon (between base and middle) instead of its head support (Figure 28). Another exception is when there are three types of supports (pylon, headland and ground) in modelling.

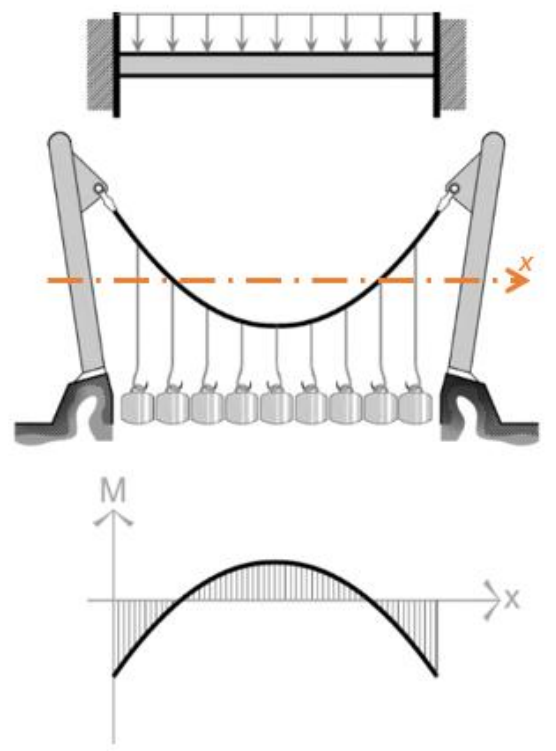

Figure 28. A hyperstatic fixed at both ends beam with uniformly distributed load as an exception to the method

In this case, it should be assumed the level of the headland and ground the same; each support retains their characteristics but at the same level to another (Figure 29). So, in this case, the ground support should not be located lower than the headland one. All other rules will not void at all.

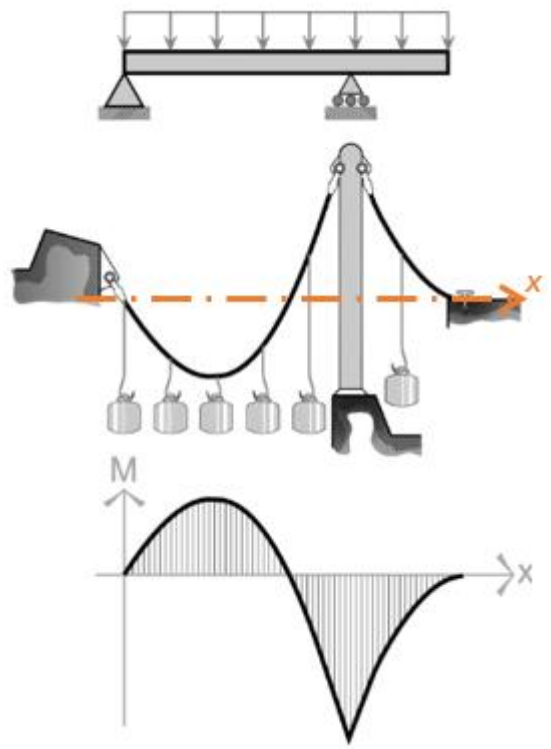

Figure 29. An overhanging beam with uniformly distributed load as another exception to the method

\subsection{Catenaries in Portal Frames Form Finding}

Masonry materials (stone, brick, adobe, etc.) just can bear compressive stresses and when tension posed on such materials they will fail because of occurring cracks. Nature chooses catenary based arch shapes for anticlines and natural bridges and arches (Figure 30). Several architectural ordonnances and nations had found out this axiom by trying and error constructing and using same approach to design their ancient structures.
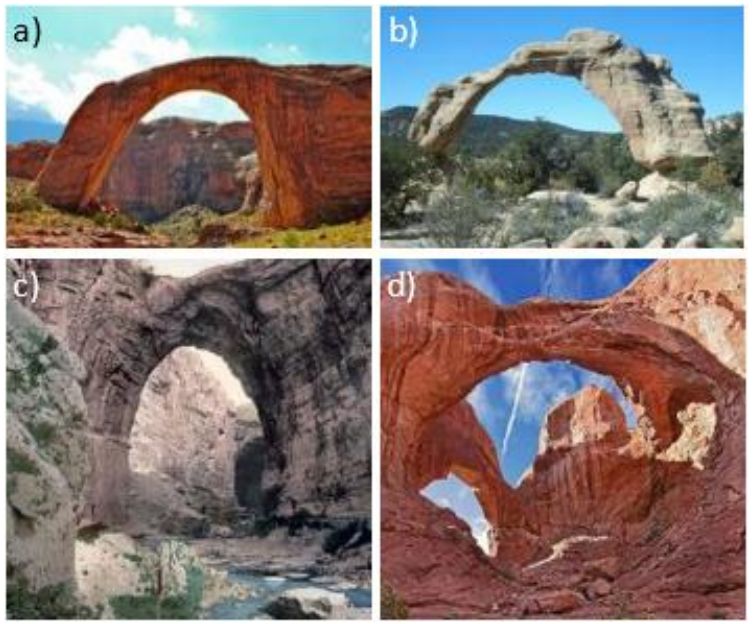

Figure 30. atural arches shaped by natural planation: a) Rainbow Bridge, Utah, USA (Photo by: Kate Nay); b) New Mexico Anasazi Arch (Photo by: Arch Larry); c) A natural arch bridge, Constantine, Algeria (Source: www.old-picture.com); d) Natural double arches, Utah, USA (Photo by: Flicka).

On the next step of evolution, constructing flat roofs architects tried to make post-lintels and this theory to design and construct portal frames, in order to have straight elements in frame instead of curved one, behaviour of frame elements inclined toward composite behaviour (bending) instead of pure behaviour (compression).

Therefore the best algorithm to design tapered portal frames based on catenaries (the optimum forms) is:

1) Finding catenary form of span which be designed;

2) Inverting the form of catenary to find load path of arch (best form for arch axis);

3) Defining form and height of portal frame which we want to design;

4) Designing depth of portal members according to catenary form. The more distance of catenary the more depth of member.

For first example, consider Figure 31-a as a given portal frame with specified span and height. The aim is estimating depth changing of its members by a rule of thumb. First, according to loading condition posed on the portal frame, we should find catenary form of contemplated span under such condition. In intersection points between portal frame and catenary form, we define pin joint because in such points there is no bending 
moment. Also around the pin joint, the member becomes narrow ${ }^{9}$. By going away from the catenary form, designer should increase the depth of the member to increase cross section moment of inertia because bending moment increases in such points.

As we know pin connections does not transfer bending moment and just is able to transfer axial and shear forces. So, where portal meets the catenary form, we locate a pin joint there (Figure 31-c) and wherever our portal frame goes away from catenary (Figure 31-b) we should increase depth of members (increasing moment of inertia) for bearing more posed bending moments. a)

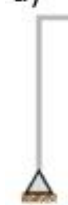

c)

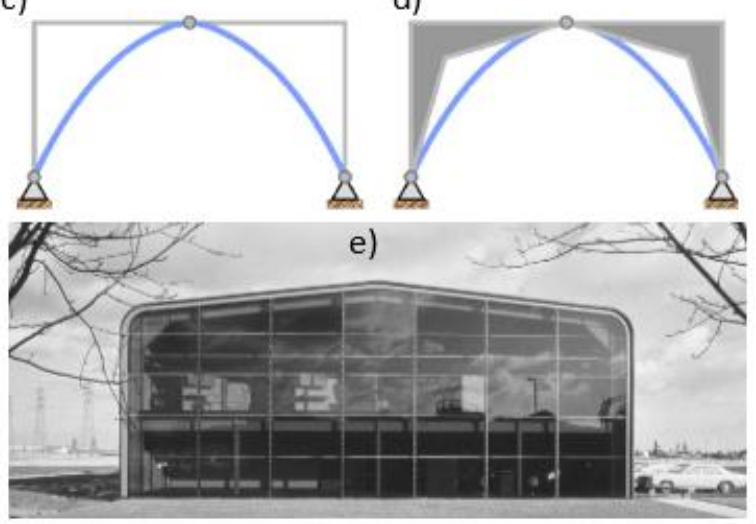

b)
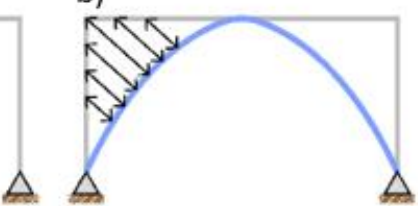

d)

d

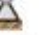

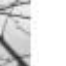

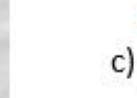

c)
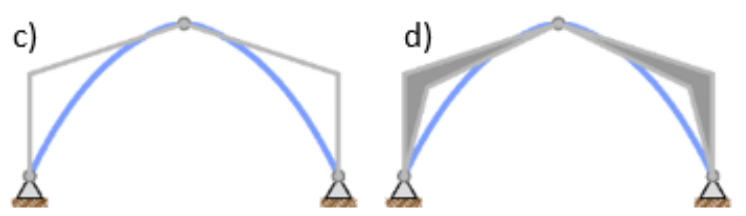

and catenary form. d) Defining depth of members

a)
Figure 31. Catenary-based design of a single-story single-span tapered portal frame: a) Schematic contemplated form of portal frame; b) Inverted catenary form of this span; c) Locating pin joint for intersections of portal frame form and catenary form. d) Defining depth of members as for distance of each point from catenary form. e) Expressed tapered portal frame behind of glazed-end elevation of a building for Modern Art Glass, Foster and Partners. (Source: [16])

Let us consider another example in which we want to design a single-bay portal frame with pitched roof. By taking the similar approach used in previous example, we take catenary form first. Hereafter, determining the depth according to distance from catenary form is the second step. Final optimized shape of portal frame is Fig. 32-d

This approach is not just limited to symmetrical and beeline portal frames. We can use this pattern for all portal frames like Fig. 33 and Figure 34. It should be mentioned that increasing the depth of left side member is more than the right one because distance between frame axes to catenary form is more in left side.

9 The less bending moment, the less cross section moment of inertia.
Figure 32. Catenary-based depth design of a single-storey pitched roof portal frame: a) Contemplated form of frame; b) Inverted catenary form of this span; c) Locating pin joint for intersections of portal frame form
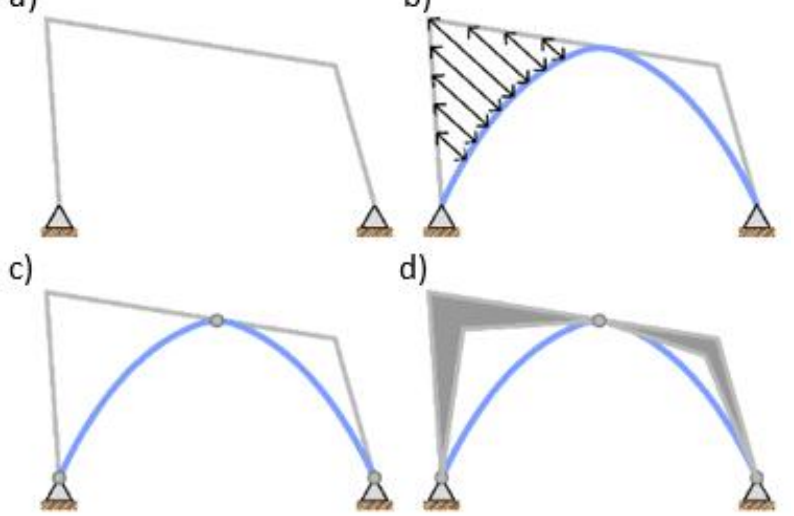

As it is stated before, designers can design curved frames by smoothening the edges. Such frames are more eye-catching than pike frames. Hence we can design the frame in Figure 33 as Figure 34 or Figure 31 as Figure 35.

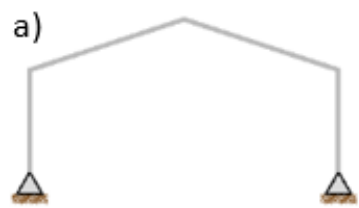

Figure 33. Catenary-based depth design of a single-storey unsymmetrical portal frame

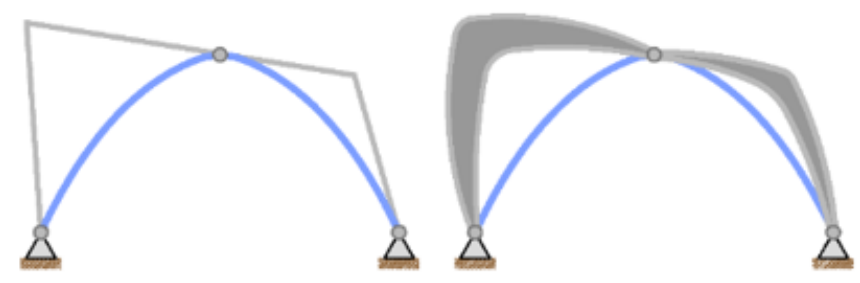

Figure 34. Catenary depth design of a single-storey asymmetrical portal frame with curved edges

Three-hinged frames is not only choice of designing tapered portal forms. Generally, there are two options for designing such frames (with rigid connection between beam and columns), one option as described before is a three-hinged frame and another one is two-hinged frame. We cannot insert more than three hinges in a two-dimensional frame because it will be unstable. It is worth noting that if the apex of parabola is higher than frame, the area under frame should be equal to the area which is under centerline of the frame.

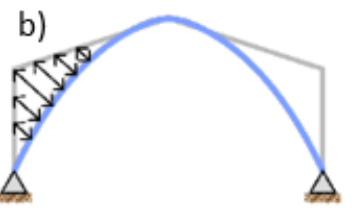


By changing the height or span of the catenary form, we have more alternatives. Architects put upon of several joints (hinge like narrowing region) layouts in façade of frame and can impart visual effects of tapering and thickening of structural elements (Figure 36).
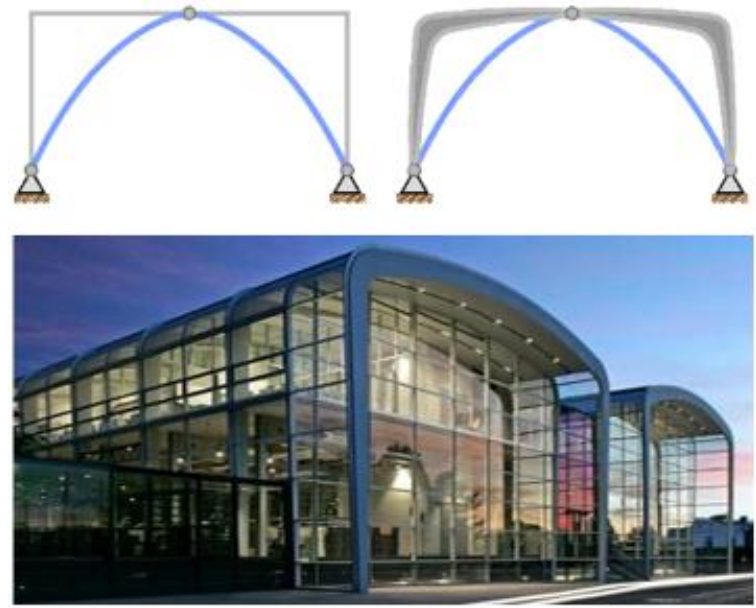

Figure 35. atenary-based depth design of a single-storey curved portal frame: a) Schematic contemplated form of portal frame; b) Final form of tapered portal frame. c) Tapered curved portal frame in Gira Production Facility, Radevormwald, Germany, Ingenhoven Architekten.(Source:[17])

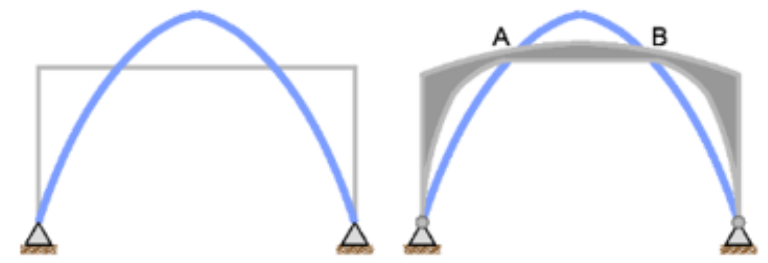

Figure 36. Another alternative of tapered portal frame with higher catenary form (A two-hinged frame). But it is not possible to locate real pin joint in intersections of frame axis to catenary form (A and B) because four hinges make the frame unstable. So in these points frame become thinner (less depth) but not like a hinge

A real example of this type of frames is designed by AP Brunnert and Partner in ICE Railway Station (Figure 37). Frangibility of supports shows hinged support and upper part of frame is also thin. In contrary, the connection between beam and columns is thick because there is farther distance from catenary form and frame should bear huge bending moments.

\subsubsection{Finding the Tapered Form of Portal Frames Using Catenary-Based Rule of Thumb}

It can be mathematically proved by methods like separation of elements and draw bending moment diagrams separately then design elements according to diagrams.

Let us design a portal frame like which is illustrated in Figure 31-a again by not using a single bay catenary (as described before). It can be assumed as a portal frame (rigid connection between beam and columns) subjected to gravitational loads. Deformation of frame under this load condition is like Figure 38-b and when diagram drawn (separately for each elements) it will be similar to Figure 38-c and optimum form will be like Figure 39-d, increasing the height of section in regions that have more bending moment and decreasing height in low-bending-moment regions.
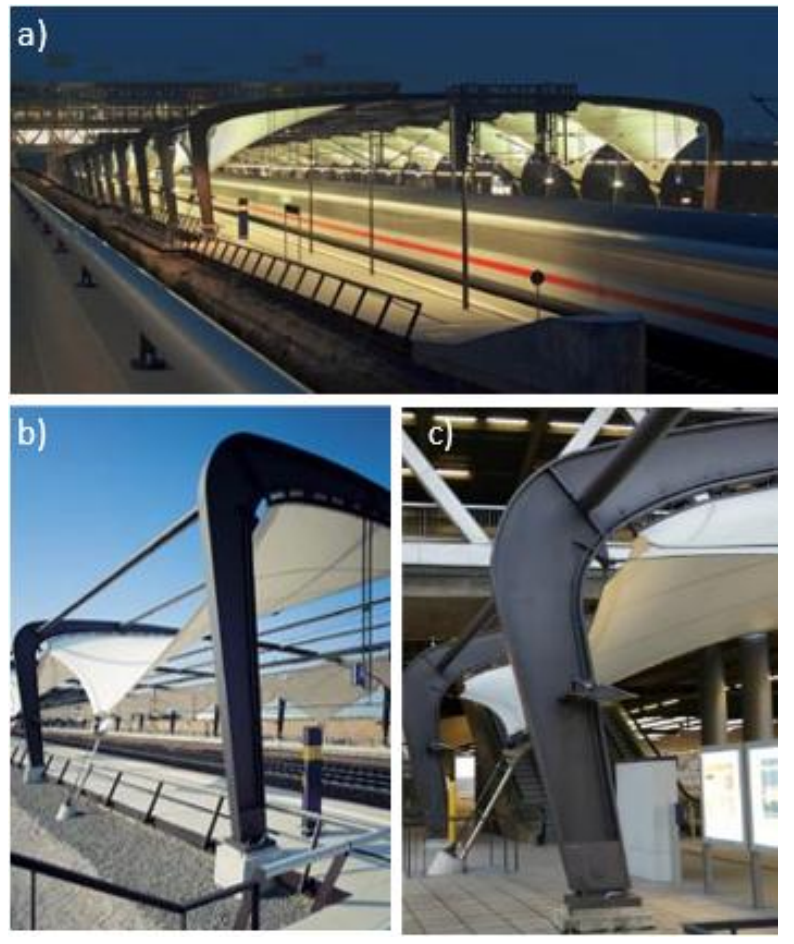

Figure 37. Catenary-based depth design of a single story symmetrical portal frame in ICE railway station, Leipzig-Halle Airport, Germany, AP Brunnert and Partner: a) Full view of frame; (source of image:[18]) b) Side view of frame; (source of image:[18]) c) Detail of section. (source of image:[19])

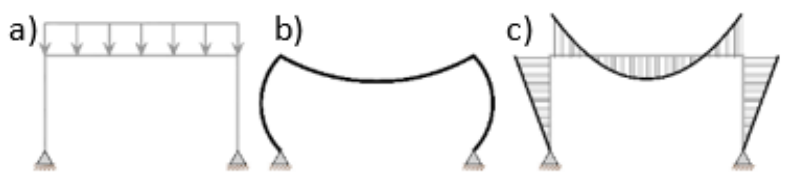

Figure 38. Finding optimum form of portal frame not using single-bay catenary: a) A given portal frame; b) Deformation of frame under the load; c) Bending moment diagram of frame

The main scope of this paper is a catenary-based rule of thumb design not mathematical approaches, so in another way we try to draw diagrams via separating elements and simulation with the catenary-based method described before. In this way, we first suppose there are three beams connected to each other (a horizontal beam under distributed load perpendicular to its axis and two under axial compression and a concentrated couple due to rigid connection reaction).

The rigid connection between beam and columns makes the beam like a beam fixed at both ends so it can be assumed as a catenary supported by two pylon and is subjected to distributed load (Figure 39-b). Hence two columns are like cables which are supported by pylon in 
upper point and by a headland support in lower point.

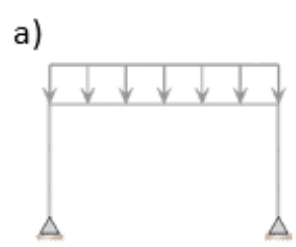

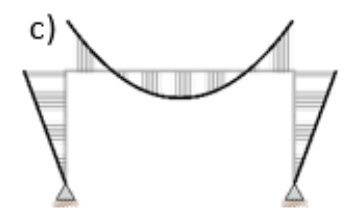

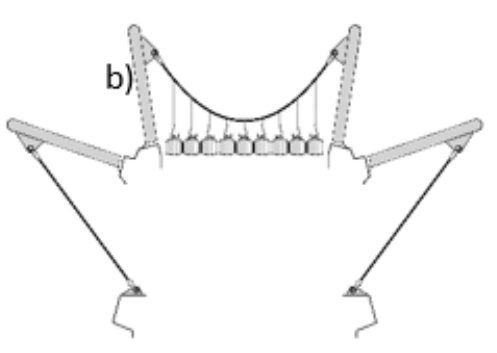

d)

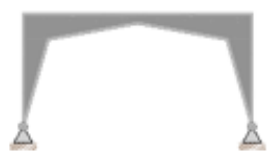

Figure 39. Finding the optimum form of a given portal frame not using single-bay catenary and modelling by separated elements using catenary-based rule of thumb method: a) Portal frame condition; b) Modelling via catenary-based method; c) Bending moment diagram of the frame; d) Optimum form of the frame a)
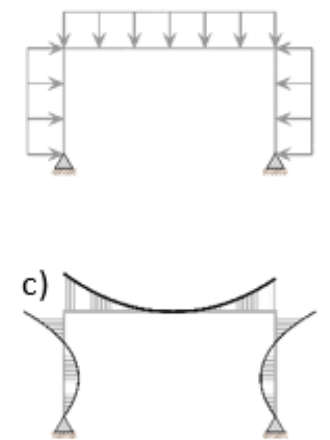

b)

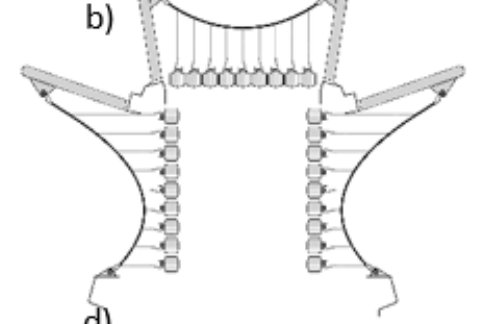

d)

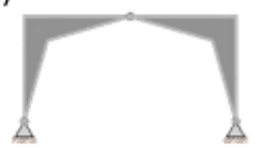

Figure 40. Finding the optimum form of a portal frame illustrated in Figure 31 not using the single-bay catenary and modelling by separated elements using SE method: a) Portal frame condition; b) Modelling by the rule of thumb method; c) Bending moment diagram of frame; d) Optimum form of the frame

The difference between Figure 39-d and Figure 31-d is the pin in the centre of the beam that arises from differences in modelling approach and both two answers are correct. For a better understanding of difference, see Figure 40 that draws bending moment diagrams via catenary-based rule of thumb method. The fundamental difference between the portal frames in Figure 31 and 40 is in loading condition. In Figure 31 when we modelled frame with catenary, we assumed the whole of frame is under distributed load because the curvature of arch, effect of load (its components) is higher. So, effect of lateral loads on columns create bending in columns more than Figure 40 and this makes the bending in beam less than which occurred in Figure 39. For comparison between these two examples in a similar view, form finding of portal frame in Figure 31-a is designed again in Figure 40 by the rule of thumb bolding the differences well.

However, the basic principles can be used in designing truss frames as well, the prospect of designing of a tapered truss is that design and construct of pin joint is easier in truss frames. It is enough to lengthen some members around higher depth of section to increase depth of section (Figure 41). Hence, if we model truss frame as a single-bay catenary (like the portal frame in Figure 31-a) the result of optimization will be as illustrated in Figure 41.

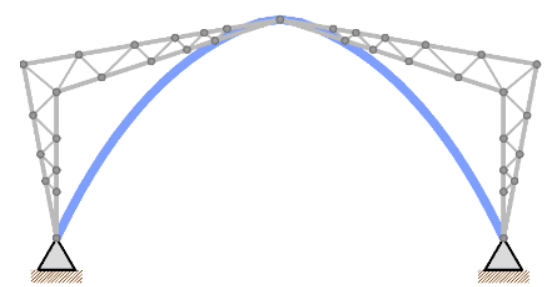

Figure 41. Catenary-based depth design of a single-storey truss portal frame. The theory is the same as I section portal frames but increasing or decreasing in height of section is done by changing in length of truss members

\subsubsection{Finding the Tapered Form of a Beam Using Catenary-Based Rule of Thumb}

The main stress defining behavior of beams is bending. The central idea in optimizing tapered beams is adopting cross section of a given beam according to the bending moment diagram but it is the solution when beam is mainly subjected to bending moment (Figure 42). Therefore if another stresses (like pure compression, tension, torsion, etc.) are posed on the beam, the answer cannot be found so easily.

a)

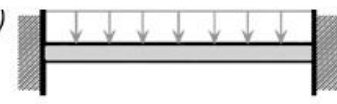

b)

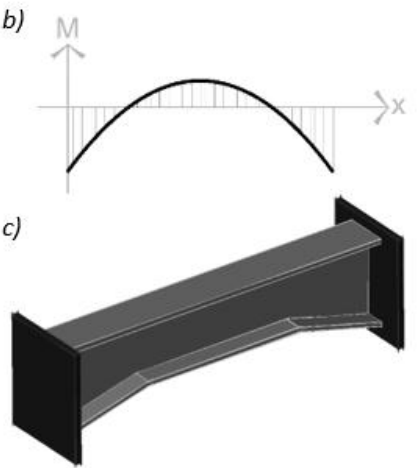

Figure 42. Gradually tapered form in a beam fixed at both ends under distributed load

Figure 42 shows a gradual tapering form for a floor beam that inclined bottom wing is substitute for several strengthening plates. Considering inclined wing, there is another option. Curved wing (Figure 43) is the most efficient from structural optimization point of view because it coincides closely with bending moment 
diagram. But its producing is hard and needs rolling process in factory.

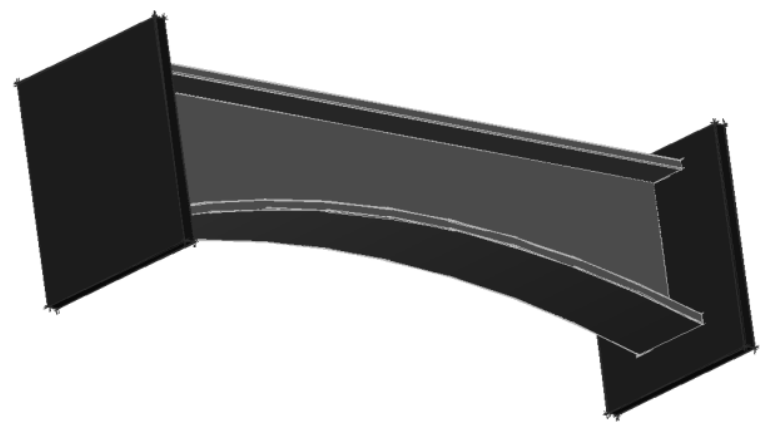

Figure 43. Another option (curved wing) that is best for fixed at both ends beam (under distributed load)

\section{Conclusions}

Despite its exploratory nature, this study offers some insight into analogies between natural forms and human-designed structures.

Nature-inspired forms are widely employed in engineering applications. Hence, mimicking perfect natural morphology of structures will assist designers to identify some conformities in the process of classic methods of design due to several correspondences in load path patterns. In addition to that, the preliminary design of structural forms which is undertaken by architects, entails a comprehensive view of structural behaviour. The concept needs familiarity to some fundamental numerical models which are totally slow and misconstrued. Finding such heuristic approaches not only facilitates structural behaviour perception to structural engineers, but also eases architects' cognition of structural principles and design morphology. Such nature-inspired models that develop BMDs from tension-only forms are highly applicable in structural analysis as well as optimization modelling. They also provide a good platform for educational purposes.

\section{REFERENCES}

[1] A. L. Nelson, K.W.F.a.M.C., Differential Equations. 1952, Boston: D. C. Heath \& Co.

[2] Fahie, J.J., Galileo, his life and work. 1903: J. Pott.
[3] Jardine, L., Monuments and microscopes: Scientific thinking on a grand scale in the early Royal Society. Notes and Records of the Royal Society of London, 2001. 55(2): p. 289-308.

[4] Poleni, G. and J. Poleni, Memorie istoriche della gran cupola del tempio Vaticano e de'danni di essa $e$ detristoramenti loro, divisi in libri 5. 1748: Nella Stamperia del seminario.

[5] Bechthold, M. and D.L. Schodek, Structures. 2007: Pearson Education.

[6] Motro, R., An anthology of structural morphology. 2009: World scientific.

[7] Collins, G.R. and A. Gaudí, New York: George Braziller. 1960, Inc.

[8] Margolius, I., Architects+ engineers= structures. 2002: Academy Press.

[9] Lewis, W., Mathematical model of a moment-less arch. Proceedings of the Royal Society A: Mathematical, Physical and Engineering Sciences, 2016. 472(2190): p. 20160019.

[10] Mainstone, R., Developments in structural form. 2013: Routledge.

[11] Chilton, J.C. and H. Isler, Heinz Isler: the engineer's contribution to contemporary architecture. 2000: Telford.

[12] Larsen, O.P. and A. Tyas, Conceptual structural design: bridging the gap between architects and engineers. 2003: Thomas Telford.

[13] Kotnik, T. and J. Schwartz, The architecture of heinz isler. Journal of the international association for shell and spatial structures, 2011. 52(3): p. 185-190.

[14] Isler, H. Twenty-five years attempt for structural beauty. in IABSE Congress Report. 1980.

[15] Roylance, D., Statics of Bending: Shear and Bending Moment Diagrams, C. Massachusetts Institute of Technology, Editor. 2000, Department of Materials Science and Engineering.

[16] Trebilcock, P. and R.M. Lawson, Architectural design in steel. 2004: Taylor \& Francis.

[17] Architekten, I. March 2013]; Available from: http://www.ingenhovenarchitects.com.

[18] Partner, a.B.a. ICE railway station, Leipzig-Halle Airport, Germany. August 2013]; Available from: http://www.ap-br unnert.de/index_english.html.

[19] Structures), S.I.D.a.G.o. ICE railway station. August 2013]; Available from: http://en.structurae.de/structures/dat $\mathrm{a} /$ index.cfm?ID=s0021077. 